Originally published as:

Besier, T., Hölling, H., Schlack, R., West, C., Goldbeck, L.

Impact of a family-oriented rehabilitation programme on behavioural and emotional problems in healthy siblings of chronically ill children

(2010) Child: Care, Health and Development, 36 (5), pp. 686-695.

DOI: 10.1111/j.1365-2214.2010.01085.x

This is an author manuscript.

The definitive version is available at: http://onlinelibrary.wiley.com/ 


\title{
Impact of a family-oriented rehabilitation programme on behavioural and emotional problems in healthy siblings of chronically ill children
}

\author{
T. Besier, ${ }^{*}$ H. Hölling, ${ }^{\dagger}$ R. Schlack, ${ }^{\dagger}$ C. West ${ }^{\ddagger}$ and L. Goldbeck ${ }^{*}$ \\ * University Hospital Ulm, Department of Child and Adolescent Psychiatry/Psychotherapy, Ulm \\ ${ }^{\dagger}$ Robert-Koch Institute, Berlin \\ ${ }^{\ddagger}$ After-Care Clinic for Children with Chronic Illness, Tannheim, Germany \\ Correspondence: \\ Tanja Besier, University Hospital for Child and Adolescent Psychiatry/ Psychotherapy, Steinhoevelstr. \\ 5, 89075 Ulm, Germany \\ E-mail: tanja.besier@uniklinik-ulm.de
}

\begin{abstract}
Objective: To evaluate the impact of a family-oriented inpatient rehabilitation programme on behavioural and emotional problems in healthy siblings of chronically ill children and to assess the association between these problems and quality of life.

Methods: A total of 259 healthy children (4-16 years, $M=8.6$ years, $S D=3.3$ ) with a chronically ill sibling were enrolled in the study. Parents filled in the Strengths and Difficulties Questionnaire, while the children answered a self-report quality of life instrument (LQ-KID) at the time of admission and discharge from the clinic and at a 6-month follow-up. Comparisons were performed with a matched control group from the German general population $(n=777)$.

Results: Significant behavioural or emotional symptoms were found in $30.5 \%$ of the healthy siblings, the relative risk of having elevated scores being 2.2 compared with the control group. Symptoms were inversely correlated with quality of life $(r=-0.42)$. During the inpatient rehabilitation, symptoms decreased significantly to a normal level. Similarly, quality of life significantly improved, except in the dimension family relations.

Conclusions: Family-oriented inpatient rehabilitation is a promising approach to improve the mental health of children with a chronically ill sibling.
\end{abstract}

\section{Introduction}

Living with a child with a severe chronic illness such as cancer or cystic fibrosis leads to considerable demands for all family members. The family system, as a context within which the child patient exists, is an emotional unit, so that single family members cannot be seen in isolation. The experience of a lifethreatening illness challenges the balance within the family system and probably disrupts all family members (Houtzager et al. 1999). Healthy siblings of ill children also face multiple challenges, such as exposure to the physical and emotional pain of their brother's or sister's illness, fear, parental distress, and extended separation from the ill child and the parents because of hospitalizations (e.g. Alderfer et al. 2003; Houtzager et al. 2004). Several studies have shown that having a brother or sister with a chronic illness poses a risk to the healthy sibling's mental health and their psychosocial adjustment (see the meta-analysis by Sharpe \& Rossiter (2002), although many healthy siblings seem to adjust quite well. Some studies could even show beneficial effects on healthy children in families with a chronically ill child, e.g. in terms of social maturity and prosocial behaviour (Ferrari 1984; Horwitz \& Kazak 1990). The Ontario Child Health Study (Cadman et al. 1988) found a twofold increased risk for internalizing disorders (such as depression and anxiety) as well as an increased risk of peer problems. In a study of adolescent siblings of childhood cancer survivors, Alderfer and colleagues (2003) demonstrated that nearly half of their sample showed at least mild symptoms of post-traumatic stress (e.g. intrusions, avoidance and arousal), as measured with the Posttraumatic Stress Disorder Reaction Index (Pynoos et al. 1987). Quality of life (QOL), a multidimensional concept including physical, 
emotional and social well-being and functioning (WHOQOL Group 1995) that has been studied extensively in recent years, also seems to be diminished in healthy siblings of ill children (Houtzager et al. 2004).

Even though it is without controversy that there is a group of siblings who show problems adapting to the illness of their brother or sister and who do need supportive interventions, empirically evaluated intervention programmes for healthy siblings are rare and have mostly used small, non-randomly assigned groups. Sidhu and colleagues (2006) evaluated a 4-day camp intervention for healthy siblings of paediatric cancer patients that was designed to provide age-appropriate information about the disease and its consequences, improve social competencies and reduce the level of distress experienced. The programme was effective in improving the mental health of the siblings, and these improvements were sustained at 8 weeks follow-up. The results are in line with other studies on integrated group interventions for siblings and parents of chronically ill children (Barrera et al. 2002; Lobato \& Kao 2002, 2005). In general, psychoeducation, that is education about all relevant aspects of a certain mental illness (e.g. characteristic symptoms, effects and consequences, ways to deal with the disease, etc.), information about chronic diseases and support groups have been shown to improve the mental health of children, leading to a better understanding of the family situation (Kibby et al. 1998; Wamboldt \& Wamboldt 2000).

In Germany, family-oriented rehabilitation programmes became popular in 1984 and are now implemented as the standard rehabilitation programme in four after-care clinics. The patients and their families, including healthy siblings, are offered a medical and multi-modal psychosocial intervention programme aimed at improving the family members' wellbeing and QOL, while taking into account special medical needs of the index patients. The effectiveness of family-oriented rehabilitation in Germany has been evaluated in several studies, mostly focusing on children with cancer and their parents. These studies tend to discuss the mental health of healthy siblings of chronically ill children only as one of the negative consequences and subsequent problems that a chronic illness poses for the whole family system (Häberle et al. 1991; Petermann et al. 1994; Kanth et al. 2001; West 2005). Therefore, the current study focuses on emotional and behavioural problems in healthy siblings of chronically ill children in Germany, evaluating the effectiveness of a family-oriented rehabilitation approach in reducing the sibling's psychopathology. Systematically analysing a clinic's basic documentation data, we tried to answer the following research questions:

1 Does the level of emotional and behavioural problems in our sample of children with a chronically ill sibling decrease during the family-oriented rehabilitation programme?

2 Is there a significant association between mental health problems and QOL?

3 Are possible beneficial effects of the intervention programme stable over a 6-month follow-up period?

In line with the literature, we expected a subgroup of healthy siblings to be experiencing elevated mental health problems, compared with a control group from the general German population, matched by age, gender and parents' educational background. We also expected decreasing levels of mental health problems during the course of the inpatient intervention programme, associated with improved QOL.

\section{Methods}

\section{Sample recruitment and procedure}

The data were collected as part of the clinic's basic documentation between May 2005 and August 2006 in accordance with the ethical standards of the local IRB at the University of Ulm. All families with a chronically ill child (cystic fibrosis, congenital heart disease, cancer) aged 4-18 years that participated in a 4-week inpatient rehabilitation programme (see below) during this time period were asked to complete the questionnaires prior to admission and at discharge from the rehabilitation clinic. The parents filled in a questionnaire including a screening measure of emotional and behavioural problems in their children [Strengths and Difficulties Questionnaire (SDQ), Goodman 1997], whereas children completed a self-report QOL questionnaire (LQ-KID, Goldbeck \& Braun 2003) if they were aged 8 years and older. Six months after discharge from the clinic, the same questionnaire was mailed to the families in order to obtain follow-up data on the stability of the effects. 
The final study sample consisted of 259 healthy children (4-16 years) from 211 families with a chronically ill child (response rate $92.8 \%$ ); 136 children provided self-reports of their QOL.A sample description can be found in Table 1 . The ill siblings of the 259 healthy children taking part in the study had either a diagnosis of cystic fibrosis ( $n=47,0-15$ years, $\mathrm{M}=8.4, \mathrm{SD}=4.0,59.6 \%$ male), or cancer $(n=100,1-17$ years, $\mathrm{M}=8.4, \mathrm{SD}=4.1)$, or congenital heart disease $(n=65,0-16$ years, $\mathrm{M}=6.1, \mathrm{SD}$ $=4.1$ ). Most of the children $(78.3 \%)$ with cystic fibrosis were not or only mildly impaired with respect to their lung function (FEV1\% > 70), whereas $8.7 \%$ showed a severe impairment (FEV1\% < 50). The most common main diagnoses of the children with cancer were leukaemia $(42.4 \%)$, brain tumour (16.2\%), lymphoid cancer (13.1\%) and bone tumour (7.1\%). Nearly two-thirds $(65.7 \%)$ had a good prognosis, whereas the prognosis was uncertain in $32.2 \%$ and very poor in $2 \%$ of the cases. The most common diagnosis of the children with congenital heart disease was a right-to-left or left-to-right shunt (29.2\% and $20.0 \%$, respectively). Of those children, $23.4 \%$ had a good prognosis, whereas the others had an uncertain $(57.8 \%)$ or infaust $(18.8 \%)$ prognosis.

At the time of discharge $235(90.7 \%)$ of the healthy children were reassessed, 24 parents and/or children declined to fill in the questionnaires a second time. Follow-up data were provided for 134 children $(51.7 \%)$ from the original sample. A comparison of those who participated in the 6-month follow-up with those who dropped out revealed no significant differences concerning the healthy sibling's age, the level of behavioural and emotional problems and the self-reported QOL at the time of discharge from the clinic.

The sample was compared with a reference group of 777 children (matched for age, gender and socio-economic status) from a recent German child health survey (KiGGs). The KiGGS study is a nationwide representative cross-sectional health interview and examination survey with a total study population of 17641 children and adolescents aged 0-17 years. The participants were medically and physically examined and tested. In addition, the parents, and from 11 years on, also the children and adolescents themselves, filled in an extensive self-administered questionnaire including questions on psychological and social areas. The data were collected from May 2003 to May 2006 at 167 representatively selected sample points all over Germany. The aim of the KiGGS study was to ascertain for the first time conjunct data on physical, psychological and social health issues according to the World Health Organization health definition [World Health Organization (WHO) 1948] for the entire age range from 0 to 17 years. More details concerning the objectives, design and measurements of the KiGGS study can be found in Kurth and colleagues 2008. Forming a comparative sample, children with a known heart disease were excluded in advance. In order to minimize a possible sample bias and to increase the statistical power for group comparisons, we used an oversampling strategy, matching one healthy sibling from our study with three controls from the survey.

\section{Inpatient rehabilitation programme}

The Rehabilitation Clinic in Tannheim in south-west Germany provides a 4-week family-oriented rehabilitation programme for families of children with childhood cancer, cystic fibrosis and congenital heart disease. While the child is admitted for rehabilitation, the ill child, the parents and the healthy siblings are treated according to an individually arranged treatment protocol. There are various treatments, including physical (e.g. medication, physiotherapy and massages) and psychosocial treatments (e.g. psychoeducative groups, relaxation techniques, psychological counselling and art therapy) for all family members. These treatments are offered together with educational and leisure programmes (e.g. handicrafts, dancing, activities with animals). The rehabilitation programme is tailored to the specific needs of each family, so the type and level of intervention varies. In general, the standard programme for an ill child comprises one appointment with the physician and on average $3 \mathrm{~h}$ of physiotherapy or educational intervention per week. Of course this varies according to the sick child's illness. Additionally, there is at least one weekly psychoeducational group session, where coping with the disease, as well as specific fears and resources of the children are discussed.

There are also specific interventions for the healthy siblings, including a psychoeducational group focussing on their particular living and family situation (one session per week), and on average three sessions of exercise, one relaxation session and one supportive or psychotherapy session per week. The contents of the interventions for the siblings depend on their specific living situation and problems. A very important issue for most of the siblings is to learn to talk about their own perceptions and desires and to be able to express such feelings as resentment and anger. Specific parent-child sessions, strengthening the often neglected relationship with the help of shared positive activities (wellness, massages, etc.) are also offered up to three times a week. The need for different interventions is assessed with the help of diagnostic screening tools (see below) at the time of 
admission to the clinic and the interventions are tailored by the psychosocial team and with the agreement of the medical doctor to meet the needs of the healthy siblings.

\section{Measures}

Parent-reported behaviour problems

The SDQ (Goodman 1997) is a brief 25-item behavioural screening questionnaire, including five subscales with five items each: emotional symptoms, conduct problems, peer relationship problems, hyperactivity-inattention and prosocial behaviour. Each of the items on the SDQ is scored on a 3-point Likert scale with $0=$ not true, $1=$ somewhat true or $2=$ certainly true, and with higher scores indicating greater problems, except on the subscale prosocial behaviour, where a higher score indicates more positive behaviour. A total difficulties score (range $0-40$ ) is obtained by summing the scores of the subscales emotional symptoms, conduct problems, hyperactivity-inattention and peer problems. The parent-report version for children aged 4-16 years was used in this study. The SDQ is a widely applied instrument that is available in more than 40 languages and has been extensively evaluated across different cultures, showing good psychometric properties (Goodman 2001; Klasen et al. 2003). For example, in a survey of 10000 children in the United Kingdom (Goodman 2001) a high internal consistency (Cronbach's a $=0.82$ ) was shown for the parent-reported total difficulties score and the retest stability over a 4 - to 6-month interval proved to be good $(r=0.72)$. Good construct validity was also found with the subscales of the well-established Child Behavior Checklist in several studies (Goodman \& Scott 1999; Van Leeuwen et al. 2006).

\section{Self-reported QOL}

The LQ-KID is an instrument for assessnig health-related QOL in 7-20 year old children and adolescents with chronic conditions (Goldbeck \& Braun 2003). In its original form the instrument contains 27 items, measuring physical well-being (nine items), psychological well-being (nine items), disease- and therapy-related distress (six items), intra-family relations (two items) and general perceived QOL (one item). In order to facilitate comparisons between scales, raw scores are linearly transformed to standard scores ranging from 0 to 100 . The instrument was validated comparing known groups with different diagnoses and levels of disease severity and its scales show good internal consistency, with Cronbach's a ranging from 0.70 to 0.88 (Goldbeck \& Braun 2003). To assess the healthy siblings' QOL, the items from the scale on disease- and therapy-related distress were omitted, as they refer to the experience of being ill oneself.

\section{Statistical analyses}

For the first assessment at admission to the programme, the proportion of elevated scores on the SDQ scales in each group were calculated, using the original cut-off scores established for the UK version of the questionnaire (http://www.sdqinfo.com). Relative risks for emotional and behavioural problems in the study group compared with the control group were determined. Paired $t$-tests were performed to assess changes in the means of SDQ scales between admission to and discharge from the rehabilitation programme and independent $t$-tests were conducted to test the significance of mean differences between the study group and the control group.

To compare the SDQ data of the study sample to that of the control group, we calculated standard deviation scores (SDS) for all points of measurement, describing the standardized difference between the two groups. A positive SDS indicated that the study participants showed more symptoms/behaviour compared with the reference group, while a negative SDS indicated less problems in the study group compared with the control group.

Pearson correlations between the SDQ total difficulties scores and the self-reported QOL scores were calculated for pre- and post-treatment. Repeated measures analyses of variance (anovas) were conducted to assess the main effect of time for the QOL scales, and for the SDQ subscales, followed by posthoc pairwise comparisons of the means. Effect sizes were calculated, with $\eta^{2}>0.01$ being small, $\eta^{2}>0.10$ being medium and $\eta^{2}>0.25$ being large effects. 


\section{Results}

\section{Prevalence of emotional and behavioural problems before rehabilitation}

Table 2 shows the proportion of elevated scores on the five subscales of the SDQ and the total difficulties score for the healthy siblings and for the matched control group.We found a 2.8-fold risk of having emotional symptoms in the study group compared with the matched control group. The prevalence of hyperactive/inattentive symptoms was increased 1.9-fold. In general, the prevalence of at least borderline elevated emotional and behaviour problems as measured by the total difficulties score was $30.5 \%$ (22.0\% being in the abnormal, clinically relevant range), thus showing a 2.2-fold increased risk compared with the general population.

Distinguishing between the three diagnoses of the ill children in the study group, no significant differences in any of the SDQ subscales or the SDQ total score of the healthy siblings could be found.

\section{Effect of inpatient rehabilitation on the level of emotional and behavioural symptoms}

Means and standard deviations of the SDQ scores at admission and discharge from the clinic and the SDQ scores of the control group are shown in Table 3.

In $90 \%$ of the healthy siblings who were able to be re-assessed at the end of the rehabilitation programme, there was a significant reduction in emotional symptoms, conduct problems, symptoms of hyperactivity/inattention and in the total difficulties score (each $P<0.001$ ). At the time of discharge from the clinic there were no longer any significant differences compared with the matched control group. SDS for the SDQ subscales at admission and discharge from the clinic are shown in Fig. 1.

Emotional and behavioural problems and QOL during inpatient rehabilitation The associations between the total difficulties score of the SDQ and the different QOL scores of the LQ-KID are shown in Table 4.

The total difficulties score and the emotional problems score correlated significantly with physical QOL, psychological QOL, family relations and total QOL. All correlations were negative.

During the inpatient rehabilitation, QOL scales improved significantly (see Fig. 2), with the exception of family relations $(\mathrm{MT} 1=80.1$ vs.MT2 $=79.2, t(115)=0.454, P=0.65)$. Effect sizes for the three improved scales ranged between $\eta^{2}=0.13$ for physical functioning and $\eta^{2}=0.19$ for global QOL.

\section{Stability of the effects at 6-month follow-up}

With regard to the 3 points of measurement (admission, discharge, 6-month follow-up), there were significant main effects of time for emotional symptoms, behavioural problems and hyperactivity/inattention $\left(P<0.001\right.$ for all three scales), with moderate effect sizes $\left(\eta^{2}=0.12-0.17\right)$; as well as for the total difficulties score $\left(F 2,130=15.080, P<0.001, \eta^{2}=0.19\right)$. No significant time effect was shown for the 'peer problems scale' $(F 2,130=1.887, P=0.16)$ nor for the prosocial behaviour scale $(F 2,130=1.890, P=0.16)$.

Post-hoc comparisons among the means for discharge and 6-month follow-up revealed significant increases in symptoms for the behavioural problems scale $(P=0.001)$, the hyperactivity/inattention scale $(P=0.01)$ and the total difficulties score $(P=0.001)$, whereas the level of emotional problems did not change significantly and stayed low.

Standard deviation scores for the SDQ subscales at admission to the clinic and 6-month follow-up are shown in Fig. 1. 


\section{Discussion}

To our knowledge, this is the first longitudinal study in a German population of children with a chronically ill sibling, which assesses the effectiveness of a family-oriented inpatient rehabilitation programme to reduce emotional and behavioural problems.

Comparisons of psychosocial outcomes with a control group from the German general population, matched by age, gender and educational background of the parents, were provided. The children with a chronically ill sibling were found to be at a more than twofold increased risk of mental health problems compared with the matched control group. Consistent with our hypothesis, and in line with a meta-analysis from the literature (Sharpe \& Rossiter 2002) nearly one-third of our sample showed at least borderline elevated levels of emotional and behavioural problems. Emotional symptoms were the most prevalent, this result being in line with the Ontario Child Health Study (Cadman et al. 1988). This might be explained by the many conflicting emotions these children may have to face in the context of their sibling's illness, such as fear (of their brother's or sister's death), jealousy and anger (because the sick child attracts a lot of parental attention), loneliness or feelings of isolation (Houtzager et al. 2004).

As expected, a significant decrease in mental health problems and a significant QOL improvement could be observed during the course of the inpatient stay, probably indicating the effectiveness of the family-oriented rehabilitation programme, where the healthy siblings received special interventions which went beyond the transfer of knowledge about the disease. Intervention studies with siblings of chronically ill children are generally scarce, even though different programmes have been developed, mostly for siblings of childhood cancer patients (e.g. Adams-Greenly et al. 1986; Heiny et al. 1990; Mclinden et al. 1991; Dolgin et al. 1997). The extent of the healthy siblings' mental health problems that was reported by their parents at time of admission to the rehabilitation clinic, as well as the behavioural and emotional symptoms' negative association with self-reported QOL, both show that these children have special needs and are at risk of developing psychiatric disorders. Hence, putting a focus on the healthy siblings of chronically ill children seems to be important.

It is important to note that no changes on the QOL subscale 'quality of family relations' were reported by the children themselves over the course of the inpatient rehabilitation. When interpreting this effect one should note that the scale consists of only two items and is thus psychometrically not particularly sound. Already at admission to the rehabilitation clinic the quality of family relations was rated to be at a very high level and there might have been a ceiling effect. One could speculate that family relations may be particularly close in families carrying the burden of a chronically ill child, e.g. as an effect of increased family cohesion. Furthermore, because of the fact that the ill child possibly draws a lot of the parents' attention, it can be assumed that the healthy sibling's satisfaction with family relations would not easily change during a 4-week inpatient stay.

The effects of the intervention programme on the emotional problems of the healthy siblings proved to be stable over a 6-month follow-up period, while the positive effects on behavioural problems, hyperactivity/inattention and the total problem score decreased over time. Thus, the intervention programme might be more effective at improving the emotional well-being of the siblings enduringly, compared with other dimensions of problem behaviour. Different baseline prevalences of specific symptoms might also be responsible for this finding. Emotional symptoms were the most frequently reported problem category before the intervention, and therefore an enduring remission was more likely to meet the significance level at follow-up, considering the limited statistical power because of the moderate sample size. It should also be noted critically that only half of the families participated in the follow-up measure, 6 months after discharge from the clinic.

It is important to address several limitations of the current study. Most importantly, because of the naturalistic study design (analysis of a clinic's basic documentation) no prospective control group was included; neither could randomized assignment to intervention or control group be performed. Therefore the effects found cannot be interpreted as specific for the rehabilitation programme provided to the study participants. However, we were able to compare the level of behavioural and emotional problems to a representative sample of German children matched for age, gender and educational background of the parents, thus enabling at least a comparison with healthy children from the normal population. Unfortunately there was only one assessment of emotional and behavioural symptoms in the control group, thus there was no evidence for the stability of symptoms over time. Additionally, the sample analysed was non-representative and self-selective and no information could be obtained on 
the non-participating families. There was also significant sample attrition, even though comparative analysis revealed no significant differences between the families participating in the follow-up measure and those that refused to complete the questionnaires after discharge from the clinic. All data were collected in one rehabilitation clinic so that the results cannot be generalized to other similar rehabilitation programmes. Because of our study design, we were not able to determine the effects of the different components of the rehabilitation programme separately. Thus, we cannot estimate which factors of the intervention programme might be responsible for the improvement of outcome variables.

Furthermore, the study focus was on the general impact of a chronic illness on healthy siblings and the effectiveness of the rehabilitation programme, even though the different chronic illnesses and their consequences (e.g. life-threatening, lifeshortening, treatable but disruptive, etc.) are likely to have a different impact upon the healthy siblings. Further studies should aim to disentangle the effects of the different health prospects on the healthy siblings and families of the ill children.

\section{Conclusions}

Taken together, this study replicates previous findings on the risk of children with a chronically ill sibling to develop mental health problems. The current study adds further data on QOL, which was found to be negatively correlated with the children's psychopathology. It also provides preliminary data in support of the effectiveness of a multi-modal family-oriented inpatient rehabilitation programme for healthy siblings. Although a large proportion of the healthy siblings showed no significant mental health problems, it was shown that there is a considerable number of healthy siblings with relevant emotional and behavioural problems. Taking part in the family-oriented inpatient rehabilitation was effective in reducing this psychopathology and had a lasting effect on the healthy siblings' emotional wellbeing. In order to stabilize and expand the beneficial effects of the rehabilitation programme, more individualized outpatient interventions should be provided, focussing on all family members in need.

In future studies it would be interesting to identify risk factors for the development of behavioural and emotional problems, which might help to tailor existing resources to meet the different needs of the familymembers. Therefore, the effects of the different chronic illnesses and their consequences (lifethreatening; life-shortening; treatable but disruptive, etc.) upon the healthy sibling's well-being should be analysed in more detail.

Additionally, more intervention studies for children with a chronically ill sibling are warranted, and evidence of the effectiveness of specific interventions should be provided by randomized controlled study designs.

\section{References}

Adams-Greenly, M., Shiminski-Maher, T., McGowan, N. \& Meyers, P. A. (1986) A group program for helping siblings of children with cancer. Journal of Psychosocial Oncology, 4, 55-67.

Alderfer, M. A., Labay, L. E. \& Kazak, A. E. (2003) Brief report: does posttraumtic stress apply to siblings of childhood cancer survivors? Journal of Pediatric Psychology, 28, 281-286.

Barrera, M., Chung, J. Y. \& Fleming, C. F. (2002) A group intervention for siblings of pediatric cancer patients. Journal of Psychosocial Oncology, 22, 21-39.

Cadman, D., Boyle, M. \& Offord, D. (1988) The Ontario child health study: social adjustment and mental health of siblings of children with chronic health problems. Journal of Developmental and Behavioral Pediatrics, 9, 117-121.

Dolgin, M. J., Somer, E., Zaidel, N. \& Zaizov, R. (1997) A structured group intervention for siblings of children with cancer. Journal of Child and Adolescent Group Therapy, 1, 3-18.

Ferrari, M. (1984) Chronic illness: psychosocial effects on siblings. Journal of Child Psychology and Psychiatry, 25, 459-476.

Goldbeck, L. \& Braun, R. (2003) LQ-KID - Ein computergestütztes Verfahren zur Erfassung der Lebensqualität chronisch kranker Kinder und Jugendlicher. Prävention und Rehabilitation, 15, 117126.

Goodman, R. (1997) The Strengths and Difficulties Questionnaire: a research note. Journal of Child Psychology and Psychiatry, 38, 581-586.

Goodman, R. (2001) Psychometric properties of the Strengths and Difficulties Questionnaire (SDQ). Journal of the American Academy of Child and Adolescent Psychiatry, 40, 1337-1345. 
Goodman, R. \& Scott, S. (1999) Comparing the Strengths and Difficulties Questionnaire and the child behavior checklist: is small beautiful? Journal of Abnormal Child Psychology, 27, 17-24.

Häberle, H., Weiss, H., Fellhauer, S. \& Schwarz, R. (1991) Familienorientierte Nachsorge als Mabnahme der Rehabilitation und sekundären Prävention für krebskranke Kinder und ihre Familien. Klinische Pädiatrie, 203, 206-210.

Heiny, S. P., Goon-Johnson, K., Ettinger, R. \& Ettinger, S. (1990) The effects of group therapy on siblings of pediatric oncology patients. Journal of Pediatric Oncology Nursing, 7, 95-100.

Horwitz, W. A. \& Kazak, A. E. (1990) Family adaptation to childhood cancer: sibling and family system variables. Journal of Clinical Child Psychology, 19, 221-228.

Houtzager, B. A., Grootenhuis, M. \& Last, B. F. (1999) Adjustment of siblings to childhood cancer: a literature review. Supportive Care in Cancer, 7, 302-320.

Houtzager, B. A., Grootenhuis, M. A., Caron, H. N. \& Last, B. F. (2004) Quality of life and psychological adaptation in siblings of paediatric cancer patients, 2 years after diagnosis. PsychoOncology, 13, 499-511.

Kanth, E., Kilborn, R., Weidenbach, A., Bretschneider-Meyer, A., Dubowy, K. O., Bode, U., Kusch, M., Krauth, K. \& Meyer, H. (2001) Familienorientierte Rehabilitation bei angeborenen Herzfehlern: Erste Ergebnisse einer empirischen Studie als Antwort auf aktuelle Fragen. Kinder- und Jugendarzt, 32, 248-250.

Kibby, M. Y., Tyc, V. L. \& Mulhern, R. K. (1998) Effectiveness of psychological intervention for children and adolescents with chronic medical illness: a meta-analysis. Clinical Psychology Review, 18, 103117.

Klasen, H., Woerner, W., Rothenberger, A. \& Goodman, R. (2003) Die deutsche Fassung des Strenghts and Difficulties Questionnaire (SDQ-Deu) - Übersicht und Bewertung erster Validierungsund Normierungsbefunde. Praxis der Kinderpsychologie und Kinderpsychiatrie, 52, 491-502.

Kurth, B.-M., Kamtsiuris, P., Hölling, H., Schlaud, M., Dölle, R., Ellert, U., Kahl, H., Knopf, H., Lange, M., Mensink, G. B. M., Neuhauser, H., Schaffrath Rosario, A., Scheidt-Nave, C., Schenk, L., Schlack, R., Stolzenberg, H., Thamm, M., Thierfelder, W. \& Wolf, U. (2008) The challenge of comprehensively mapping children's health in a nation-wide health survey: design of the German KiGGS-Study. BMC Public Health, 8, 196.

Lobato, D. J. \& Kao, B. T. (2002) Integrated sibling-parent group intervention to improve sibling knowledge and adjustment to chronic illness and disability. Journal of Pediatric Psychology, 27, 711716.

Lobato, D. J. \& Kao, B. T. (2005) Brief report: family-based group intervention for young siblings of children with chronic illness and developmental disability. Journal of Pediatric Psychology, 30, 678682.

McLinden, S. E., Miller, L. M. \& Deprey, J. M. (1991) Effects of a support group for siblings of children with special needs. Psychology in the Schools, 28, 230-237.

Petermann, F., Kroll, Th. \& Schwarz, B. (1994) Familienorientierte Rehabilitation krebskranker Kinder. Peter Lang, Frankfurt, Germany. Pynoos, R., Frederick, S., Nader, K. \& Arroyo, W. (1987) Life threat and posttraumatic stress in school age children. Archives of General Psychiatry, 44, 1057-1063.

Sharpe, D. \& Rossiter, L. (2002) Siblings of children with a chronic illness: a meta-analysis. Journal of Pediatric Psychology, 27, 699-710.

Sidhu, R., Passmore, A. \& Baker, D. (2006) The effectiveness of a peer support camp for siblings of children with cancer. Pediatric Blood \& Cancer, 47, 580-588.

Van Leeuwen, K., Meerschaert, T., Bosmans, G., De Medts, L. \& Braet, C. (2006) The strengths and difficulties questionnaire in a community sample of young children in flanders. European Journal of Psychological Assessment, 22, 189-197.

Wamboldt, M. Z. \& Wamboldt, F. S. (2000) Role of the family in the onset and outcome of childhood disorders: selected research findings. Journal of the American Academy of Child and Adolescent Psychiatry, 39, 1212-1219.

West, C. A. (2005) Evaluation des familienorientierten Behandlungskonzepts der Nachsorgeklinik Tannheim am Beispiel kardiologisch erkrankter und mukoviszidosekranker Kinder und ihrer Familien. Roderer, Regensburg, Germany. WHOQOL Group (1995) The World Health Organization Quality of Life assessment (WHOQOL): position paper from the World Health Organization. Social Science \& Medicine, 41, 1403-1409.

World Health Organization (WHO) (1948) Preamble to the Constitution of the World Health Organization as adopted by the International Health Conference, New York, 19-22 June 1946. Kopenhagen: Official Records of the World Health Organization 2, WHO. 


\section{Tables and Figures}

Table 1. Sample description

Study sample $(n=259)$

\begin{tabular}{lc}
\hline Age of healthy sibling & 8.58 \\
Mean & 3.3 \\
Standard deviation & $4-16$ \\
Range & \\
Gender of healthy sibling (in \%) & 54.4 \\
$\quad$ Male & 45.6 \\
$\quad$ Female & \\
Parent status (in \%) & 10.5 \\
$\quad$ Single parent & 89.5 \\
$\quad$ No single parent & \\
Nationality (in \%) & 92.3 \\
$\quad$ German & 4.2 \\
$\quad$ Austrian & 0.8 \\
$\quad$ Turkish & 2.7 \\
$\quad$ Other \\
Type of sick child's illness (in \%) \\
$\quad$ Cystic fibrosis \\
$\quad$ Congenital heart disease \\
$\quad$ Cancer
\end{tabular}

SDQ, Strengths and Difficulties Questionnaire.

Table 2. Relative risks for the study group of healthy siblings of a chronically ill child (SG) to have an elevated SDQ score of at least borderline level in comparison with the control group (CG)

\begin{tabular}{|c|c|c|c|c|c|}
\hline \multirow[b]{2}{*}{ SDQ scale } & \multicolumn{2}{|l|}{ SG $(n=259)$} & \multicolumn{2}{|l|}{ CG $(n=777)$} & \multirow[b]{2}{*}{ Relative risk* } \\
\hline & $\%$ borderline & $\%$ abnormal & $\%$ borderline & $\%$ abnormal & \\
\hline Emotional symptoms & 12.0 & 29.0 & 6.9 & 8.0 & 2.8 \\
\hline Conduct problems & 16.6 & 23.6 & 17.9 & 15.7 & 1.2 \\
\hline Hyperactivity & 9.3 & 17.8 & 6.2 & 8.1 & 1.9 \\
\hline Peer problems & 10.8 & 17.8 & 8.6 & 11.5 & 1.4 \\
\hline Prosocial behaviour & 10.0 & 3.9 & 7.2 & 4.0 & 1.2 \\
\hline Total difficulties & 8.5 & 22.0 & 6.9 & 7.2 & 2.2 \\
\hline
\end{tabular}

*\% borderline + \%abnormal in SG/\% borderline + \%abnormal in CG.

SDQ, Strengths and Difficulties Questionnaire. 
Table 3. Means and standard deviations and group comparisons of SDQ scores at admission (T1) and discharge (T2) from the rehabilitation clinic, and a healthy control group (CG) from a German Child Health Survey, matched for age, gender and maternal education

\begin{tabular}{|c|c|c|c|c|c|c|}
\hline & & & & Group con & & \\
\hline & $(n=259)$ & $(n=235)$ & $(n=777)$ & T1 vs. CG & T1 vs. T2 & T2 vs. CG \\
\hline SDQ scale & $\mathrm{M}(\mathrm{SD})$ & $M(S D)$ & $\mathrm{M}(\mathrm{SD})$ & $\begin{array}{l}t \\
\left(P^{*}\right)\end{array}$ & $\begin{array}{l}t \\
\left(P^{*}\right)\end{array}$ & $\begin{array}{l}t \\
\left(P^{*}\right)\end{array}$ \\
\hline Emotional symptoms & $3.23(2.6)$ & $2.00(2.1)$ & $1.72(1.8)$ & $\begin{array}{l}10.510 \\
(<0.001)\end{array}$ & $\begin{array}{l}7.931 \\
(<0.001)\end{array}$ & $\begin{array}{l}2.021 \\
(0.044)\end{array}$ \\
\hline Conduct problems & $2.29(1.8)$ & $1.72(1.5)$ & $2.00(1.6)$ & $\begin{array}{l}2.448 \\
(0.015)\end{array}$ & $\begin{array}{l}6.294 \\
(<0.001)\end{array}$ & $\begin{array}{l}-2.314 \\
(0.021)\end{array}$ \\
\hline Hyperactivity & $3.89(2.7)$ & $3.15(2.5)$ & $3.08(2.3)$ & $\begin{array}{l}4.598 \\
(<0.001)\end{array}$ & $\begin{array}{l}5.577 \\
(<0.001)\end{array}$ & $\begin{array}{l}0.414 \\
(0.679)\end{array}$ \\
\hline Peer problems & $1.70(2.0)$ & $1.49(2.0)$ & $1.35(1.6)$ & $\begin{array}{l}2.744 \\
(0.006)\end{array}$ & $\begin{array}{l}1.906 \\
(0.058)\end{array}$ & $\begin{array}{l}1.092 \\
(0.275)\end{array}$ \\
\hline Prosocial behaviour & $7.71(1.8)$ & 7.89 (1.9) & $7.73(1.7)$ & $\begin{array}{l}-0.134 \\
(0.893)\end{array}$ & $\begin{array}{l}-1.809 \\
(0.072)\end{array}$ & $\begin{array}{l}1.215 \\
(0.225)\end{array}$ \\
\hline Total difficulties & $11.1(6.6)$ & $8.37(6.1)$ & $8.15(5.4)$ & $\begin{array}{l}7.154 \\
(<0.001)\end{array}$ & $\begin{array}{l}8.059 \\
(<0.001)\end{array}$ & $\begin{array}{l}0.529 \\
(0.597)\end{array}$ \\
\hline
\end{tabular}

*Bonferroni adjustment for multiple tests: $a / 6=0.01$ to reach significance; significant values are printed in bold.

SDQ, Strengths and Difficulties Questionnaire.

Table 4. Cross-correlation matrix (Spearman's Rho) for the Strengths and Difficulties Questionnaire (SDQ) total problem score and the self-reported quality of life scores at time of admission (T1) and discharge (T2) from the rehabilitation clinic

\begin{tabular}{|c|c|c|c|c|c|c|c|c|c|c|c|}
\hline & & $\mathrm{T} 1$ & & & & & $\mathrm{~T} 2$ & & & & \\
\hline & & $\begin{array}{l}\text { SDQ } \\
\text { total }\end{array}$ & $\begin{array}{l}\text { QOL } \\
\text { physical }\end{array}$ & $\begin{array}{l}\text { QOL } \\
\text { psycho. }\end{array}$ & $\begin{array}{l}\text { QOL } \\
\text { family }\end{array}$ & $\begin{array}{l}\text { QOL } \\
\text { total }\end{array}$ & $\begin{array}{l}\text { SDQ } \\
\text { total }\end{array}$ & $\begin{array}{l}\text { QOL } \\
\text { physical }\end{array}$ & $\begin{array}{l}\text { QOL } \\
\text { psycho. }\end{array}$ & $\begin{array}{l}\text { QOL } \\
\text { family }\end{array}$ & $\begin{array}{l}\mathrm{QOL} \\
\text { total }\end{array}$ \\
\hline $\mathrm{T} 1$ & SDQ total difficulties & - & $\begin{array}{l}-0.279 * * \\
(n=140)\end{array}$ & $\begin{array}{l}-0.438^{* *} \\
(n=140)\end{array}$ & $\begin{array}{l}-0.368^{* *} \\
(n=136)\end{array}$ & $\begin{array}{l}-0.416^{* *} \\
(n=140)\end{array}$ & $\begin{array}{l}0.662^{* *} \\
(n=235)\end{array}$ & $\begin{array}{l}-0.225^{*} \\
(n=123)\end{array}$ & $\begin{array}{l}-0.477^{* *} \\
(n=123)\end{array}$ & $\begin{array}{l}-0.242^{* *} \\
(n=120)\end{array}$ & $\begin{array}{l}-0.366^{* *} \\
(n=123)\end{array}$ \\
\hline & QOL physical well-being & & - & $\begin{array}{l}0.548^{* *} \\
(n=140)\end{array}$ & $\begin{array}{l}0.233^{* *} \\
(n=136)\end{array}$ & $\begin{array}{l}0.853^{* *} \\
(n=140)\end{array}$ & $\begin{array}{l}-0.127 \\
(n=128)\end{array}$ & $\begin{array}{l}0.494^{* *} \\
(n=123)\end{array}$ & $\begin{array}{l}0.436^{* *} \\
(n=123)\end{array}$ & $\begin{array}{l}0.165 \\
(n=120)\end{array}$ & $\begin{array}{l}0.538^{* *} \\
(n=123)\end{array}$ \\
\hline & QOL psychol. well-being & & & - & $\begin{array}{l}0.408^{* *} \\
(n=136)\end{array}$ & $\begin{array}{l}0.830^{* *} \\
(n=140)\end{array}$ & $\begin{array}{l}-0.263^{* *} \\
(n=128)\end{array}$ & $\begin{array}{l}0.232^{* *} \\
(n=123)\end{array}$ & $\begin{array}{l}0.449^{* *} \\
(n=123)\end{array}$ & $\begin{array}{l}0.207^{*} \\
(n=120)\end{array}$ & $\begin{array}{l}0.401^{* *} \\
(n=123)\end{array}$ \\
\hline & QOL family relations & & & & - & $\begin{array}{l}0.466^{* *} \\
(n=136)\end{array}$ & $\begin{array}{l}-0.257^{* *} \\
(n=124)\end{array}$ & $\begin{array}{l}0.181^{*} \\
(n=119)\end{array}$ & $\begin{array}{l}0.348^{* *} \\
(n=119)\end{array}$ & $\begin{array}{l}0.420^{* *} \\
(n=116)\end{array}$ & $\begin{array}{l}0.372^{* *} \\
(n=119)\end{array}$ \\
\hline & QOL total score & & & & & - & $\begin{array}{l}-0.204^{*} \\
(n=128)\end{array}$ & $\begin{array}{l}0.456^{* *} \\
(n=123)\end{array}$ & $\begin{array}{l}0.521^{* *} \\
(n=123)\end{array}$ & $\begin{array}{l}0.263^{* *} \\
(n=120)\end{array}$ & $\begin{array}{l}0.593^{* *} \\
(n=123)\end{array}$ \\
\hline $\mathrm{T} 2$ & SDQ total difficulties & & & & & & - & $\begin{array}{l}-0.187^{*} \\
(n=119)\end{array}$ & $\begin{array}{l}-0.462^{* *} \\
(n=119)\end{array}$ & $\begin{array}{l}-0.298^{* *} \\
(n=116)\end{array}$ & $\begin{array}{l}-0.349^{* *} \\
(n=119)\end{array}$ \\
\hline & QOL physical well-being & & & & & & & - & $\begin{array}{l}0.571^{* *} \\
(n=123)\end{array}$ & $\begin{array}{l}0.203^{*} \\
(n=119)\end{array}$ & $\begin{array}{l}0.879 * * \\
(n=123)\end{array}$ \\
\hline & QOL psychol. well-being & & & & & & & & - & $\begin{array}{l}0.375^{* *} \\
(n=120)\end{array}$ & $\begin{array}{l}0.818^{* *} \\
(n=123)\end{array}$ \\
\hline & QOL family relations & & & & & & & & & - & $\begin{array}{l}0.469^{* *} \\
(n=120)\end{array}$ \\
\hline & QOL total score & & & & & & & & & & - \\
\hline
\end{tabular}

${ }^{*} P=0.05,{ }^{* *} P=0.01,{ }^{* * *} P<0.001$.

$\mathrm{QOL}$, quality of life. 
Figure 1. Standard deviation scores (SDS) for the Strengths and Difficulties Questionnaire (SDQ) subscales and the total difficulties score at time of admission (T1) and discharge (T2) from the rehabilitation clinic, and at 6-month follow-up (T3). SDQ_b, behavioural problems; SDQ_e, emotional problems; SDQ_h, hyperactivity/inattention; SDQ_p, problems with peers; SDQ_pro, prosocial behaviour; SDQ_t, total difficulties score.

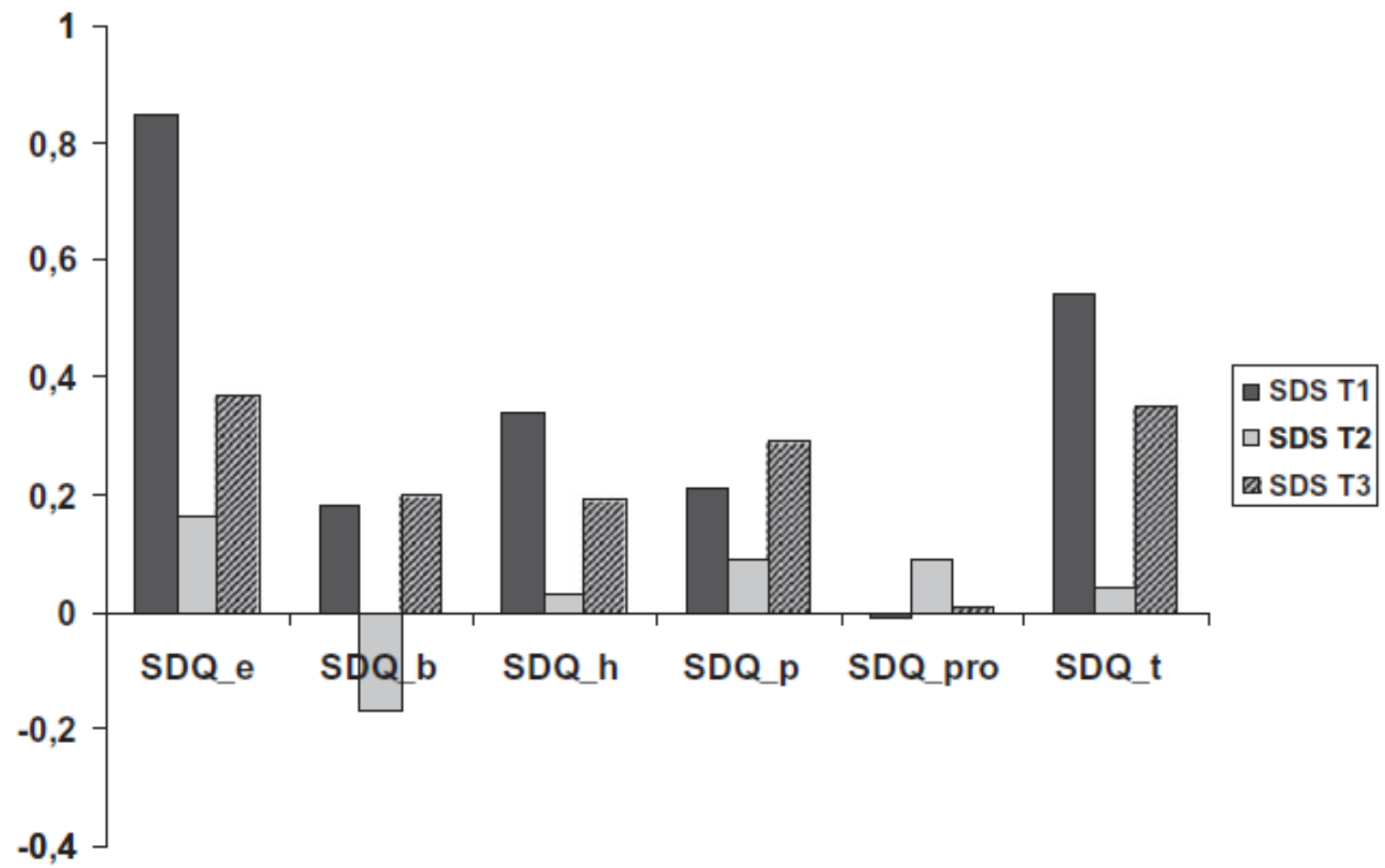

Figure 2. Mean changes in LQ-KID scales from admission (T1) to discharge (T2). ${ }^{* * *} P<0.001$.

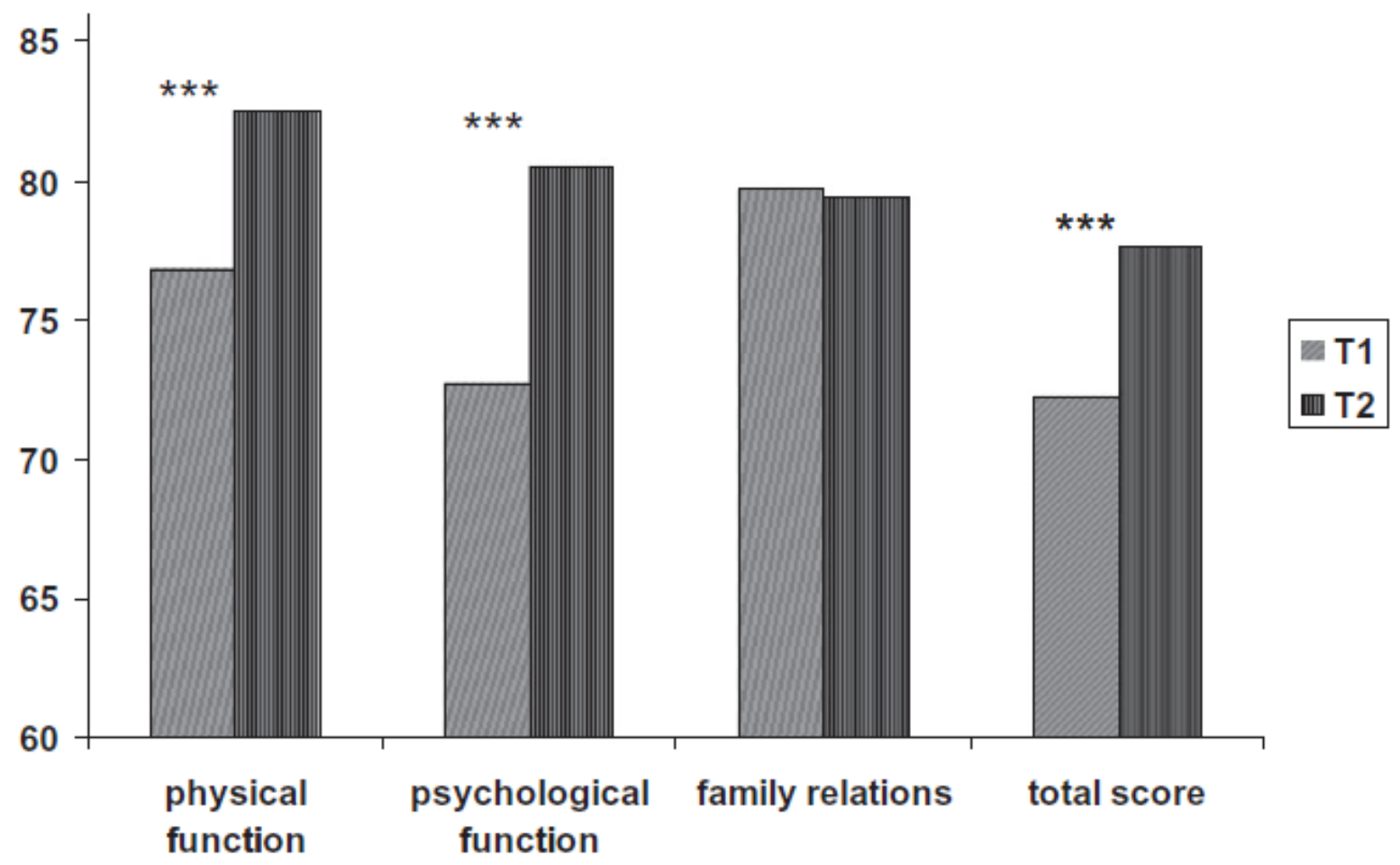

